\title{
Constraints on Correlation between the Anomalous Behaviour of Electromagnetic Normalized Functions (ENF) and the Intermediate Depth Seismic Events Occurred in Vrancea Zone (Romania)
}

\author{
Dumitru Stanica* and Dragos Armand Stanica \\ Institute of Geodynamics of the Romanian Academy, Bucharest 37, Romania
}

Received 13 February 2009, accepted 9 September 2009

\begin{abstract}
This paper is focused on a specific methodology able to emphasize the correlation between anomalous behaviour of electromagnetic normalized functions and intermediate depth seismic events which have occurred in the Vrancea zone and pointing out the main constraints related to them. The lithospheric conductivity changes produced prior to and during an earthquake, as a sequence of the dehydration of the rocks, associated with rupturing processes and fluid migration through faulting systems developed inside and close vicinity to foci, could be detected by means of the peculiar features of the electromagnetic normalized functions taken throughout the frequency range DC- $10^{-2} \mathrm{~Hz}$.

Some experiments have been dedicated to assess the robustness of a methodology using electromagnetic data acquired over a span of several years. It means that the real-time selected electromagnetic normalized functions complying with temporal invariability criterion for a 2D geoelectric structure in non-seismic condition have been analysed taking into consideration just their daily mean distribution versus seismic events recorded simultaneously.

As this methodology emphasizes the conductivity changes prior to a seismic event, it becomes an interesting subject for studying anomalous behaviour of electromagnetic normalized functions against their normal variation as possible precursors of earthquakes triggered in the Vrancea zone.
\end{abstract}

Key words: Electromagnetic precursors, Lithospheric conductivity, Earthquakes, Vrancea zone

Citation: Stanica, D. and D. A. Stanica, 2010: Constraints on correlation between the anomalous behaviour of Electromagnetic Normalized Functions (ENF) and the intermediate depth seismic events occurred in Vrancea zone (Romania). Terr. Atmos. Ocean. Sci., 21, 675-683, doi: 10.3319/TAO.2009.09.09.01(T)

\section{INTRODUCTION}

Electromagnetic research concerning a seismic hazard has been orientated for solving at least three kinds of preseismic phenomena/parameters which have occurred in the frequency ranges DC-100 MHz (Fig. 1):

- Signals possibly emitted from earthquake sources which may produce geomagnetic/geoelectric changes in ULFELF-VLF-LF-HF bands;

- Anomalous transmission of electromagnetic waves due possibly to a disturbed ionosphere related to the transmission anomaly of man made (VLF) waves and scattering of MF radio waves (VHF);

- Spatial-temporal variation of the electric conductivity in

\footnotetext{
* Corresponding author

E-mail:dstanica@geodin.ro
}

the lithosphere, associated with seismic energy release inside and/or in close proximity of foci, may be reflected by the electromagnetic normalized functions (ENF) carried out in ULF band.

For several decades numerous researchers have looked for anomalous electric/magnetic signals associated with earthquakes. In seismogenic studies many papers have been devoted to the detection of electric/magnetic signals in the ULF/ELF bands and to their correlation with seismic events of tectonic and volcanic origin (Fraser-Smith et al. 1990; Fujinawa and Takahashi 1994; Varotsos et al. 1996; Rikitake 1997; Uyeda et al. 1999, 2000, 2009; Liu et al. 2000; Nagao et al. 2000, 2002; Zeng et al. 2001; Yen et al. 2004; Varotsos 2005). Thus, the research on the relation between spatial-temporal changes of the electrical conductivity and 
seismic events has become an important subject in this direction, and the dehydration of the rocks associated with rupturing processes and fluid migration through faulting systems may also lead to noticeable increasing of the conductivity developed inside and/or in close vicinity of foci (Freund et al. 1999; Hattori 2004; Stanica et al. 2004a, 2006; Stanica and Stanica 2007; Hattori et al. 2008; Saroso et al. 2009).

In this paper the temporal variation of the electric conductivity in lithosphere, produced inside and in close proximity of Vrancea's seismogenic volume reflected by the ENF associated with seismic activity will be analysed.

\section{GEODYNAMICS OF THE VRANCEA ZONE}

The seismically active Vrancea zone is located within the arcuate portion of the Eastern Carpathians being bounded to the north-east by Scythian and East European platforms, to the South by the Moesian Platform, and westwards by the Transylvanian Basin (Fig. 2). The earthquakes are confined in a well-defined volume, $80 \mathrm{~km}$ long, $40 \mathrm{~km}$ wide and $170 \mathrm{~km}$ high, and the most of them being at an intermediate depth of $60-170 \mathrm{~km}$. The frequency-of-occurrence is about 2 - 10 events per month, with magnitude $\mathrm{M}<4$ and about $1-6$ strong events $(M \geq 7)$ per century. The crustal activity is weak, often occurred in clusters and mainly located in the depth interval of $15-40 \mathrm{~km}$.

Several geodynamic models have already been proposed for the Vrancea zone (Constantinescu and Enescu 1984; Oncescu et al. 1984; Trifu and Radulian 1989; Linzer 1996; Soloviev et al. 1999; Sperner et al. 2001; Martin et al. 2005), but a comprehensive and appropriate model is not yet available for explaining entirely the intermediate-depth earthquakes triggered in the Vrancea zone, and their lack of occurrence in the depth-interval of $60-170 \mathrm{~km}$.

Another geodynamic model, based on 3D magnetotelluric tomographic images (Stanica et al. 1999, 2004b), seems to support the idea that the inferred torsion that may result from the effects due to descending asthenospheric currents, on the one hand, and the irregular shape of the relic slab (seismogenic volume) on the other hand, is capable of generating a torque that may increase shear stress and drive faulting system and re-shearing within the rigid slab. If this is the case, then the trigger action of the intermediate depth earthquakes, in the Vrancea zone, may be interpreted as the rock response to active torsion processes induced by the complex interplay among the structure of the lithosphere and the surrounding asthenosphere, in this sector of the Eastern Carpathians.

\section{THEORETICAL BASE OF THE ELECTROMAG- NETIC NORMALIZED FUNCTIONS}

It is well known that at the Earth's surface the vertical geomagnetic component $(\mathrm{Bz})$ is an entirely secondary

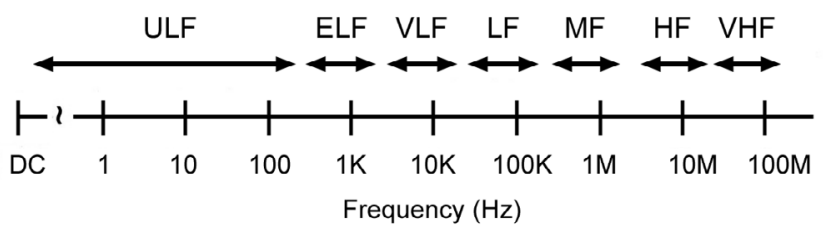

Fig. 1. Frequency ranges used to emphasize the EM precursory phenomena/parameters related to seismic activity.

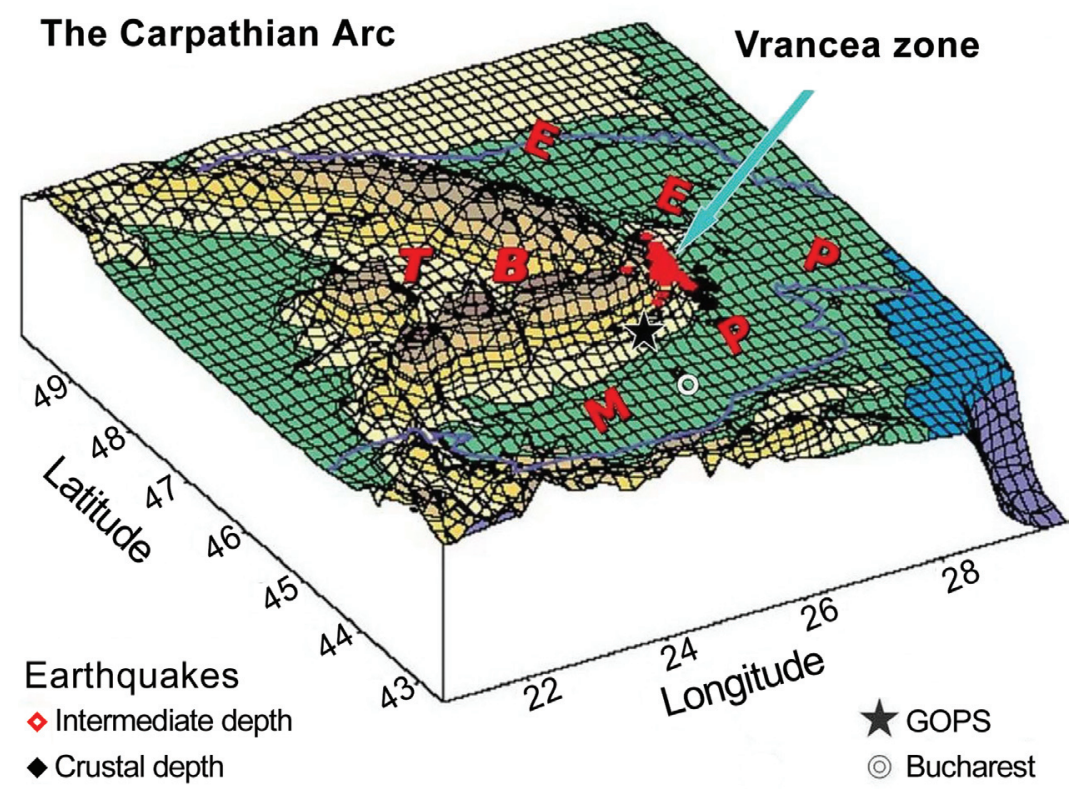

Fig. 2. Map of the Carpathian Arc Bend and the seismically active Vrancea zone: E E P is East European Platform; M P is Moesian Platform; and $\mathrm{T}$ B is Transylvanian Basin. 
field and its existence is an immediate indicator of lateral inhomogeneity (Word et al. 1970). For two dimensional structures, the $\mathrm{Bz}$ is produced essentially by the horizontal geomagnetic component perpendicular (Bperp) to strike and, consequently, a normalized function (Bzn) defined as:

$\mathrm{Bzn}=\mathrm{Bz} /$ Bperp

should be time invariant for a given 2D structure in non geodynamic conditions (Word et al. 1970), but it is unstable in geodynamic circumstances and, therefore, could be used as a precursory parameter (Stanica et al. 2006; Stanica and Stanica 2007).

Also, the absolute value of the normalized function (Bzn) is able to assess the polarity of the conductivity anomaly (i.e., whether it is more conductive than the surrounding media).

In order to define the interrelation between Bzn and electrical conductivity changes, in addition to the relation (1), we may compute the vertical resistivity Roz:

$\operatorname{Roz}=0.2 \mathrm{~T} \mid$ Epar $/\left.\mathrm{B}_{z}\right|^{2}$

where $\mathrm{T}$ is the period (s) and the Epar is the electric field parallel to strike. Also, it is possible to write the relation:

Ropar $=0.2 \mathrm{~T} \mid$ Epar $/$ Bperp $\left.\right|^{2}$

where Ropar is the resistivity parallel to strike.

Thus, in terms of resistivity (electrical conductivity) the normalized function Bzn may be estimated as:

$$
\mid \text { Bzn } \mid=(\text { Ropar } / \text { Roz })^{1 / 2}
$$

and, subsequently, the normalized function Ron may be written:

Ron $=$ Ropar $/$ Roz

Relation (4) demonstrates the fact that the Bzn could be linked to the resistivity/conductivity variation along the submerged conductive paths (fault systems) through the Earth's lithosphere.

Both normalized functions Bzn and Ron have been presented in the above text by the acronym ENF and, further on, only the correlation between anomalous behaviour of the Bzn with seismic energy release in Vrancea zone will be analysed.

\section{METHODOLOGY AND RESULTS}

As we have seen in relation (1), the normalized function Bzn could be used as a precursory parameter of seismic event measuring both the vertical component $\mathrm{Bz}$ (obtained directly from continuous monitoring of the geomagnetic field) and horizontal geomagnetic component perpendicular to the strike (Bperp) which has to be correctly evaluated by using the magnetotelluric tensor impedance decomposition technique (Bahr 1988).

In this respect, a specific electromagnetic methodology has been used, in the frame of which the next steps were performed:

- Establishment of the optimum placement of the monitoring site and pattern recognition (2D structure and strike orientation);

- Installation of the measuring system for continuous monitoring of the geomagnetic components Bz, Bperp and Bpar;

- Emphasis of the anomalous behaviour of the normalized function Bzn in order to highlight its relation with seismic events.

\subsection{Establishment of the Optimum Placement of the Monitoring Site and Pattern Recognition}

With the aim of identifying the best placement for continuous monitoring of the geomagnetic field, in the conditions mentioned above, at the Geodynamics Observatory Provita de Sus (GOPS - Fig. 2) we conducted a discrete electromagnetic (EM) observation, in the ULF band, by using the GMS 06 system (Metronix, Germany). To evaluate the geoelectric pattern under the measuring point, data processing and tensor impedance decomposition have been made with the help of MAPROS software packages and, consequently, the following basic tasks have been performed:

- Real time-display of the time series and all important EMparameters;

- Evaluation of skewness coefficients (the rectangle delimitates the frequency range where skewness coefficients are less than 0.3 what means that the geological structure is of 2D type - Fig. 3) and strike (the ellipse delimitates the frequency range where the strike orientation is about eastwest - Fig. 4, thus the Bperp time series should be carried out always perpendicular to the strike).

The skewness (S) is a dimensionality parameter of the magnetotelluric impedance tensor and it is defined as

$S=\left|\frac{|Z x x+Z y y|}{|Z x y-Z y x|}\right|$

with the error

$\Delta S=$

$\sqrt{\frac{|Z x x-\Delta Z x x|^{2}|Z y y-\Delta Z y y|^{2}}{|Z x x-Z y y|^{4}}+\frac{|Z x y-\Delta Z x y|^{2}|Z y x-\Delta Z y x|^{2}}{|Z x y-Z y x|^{4}}}$ 


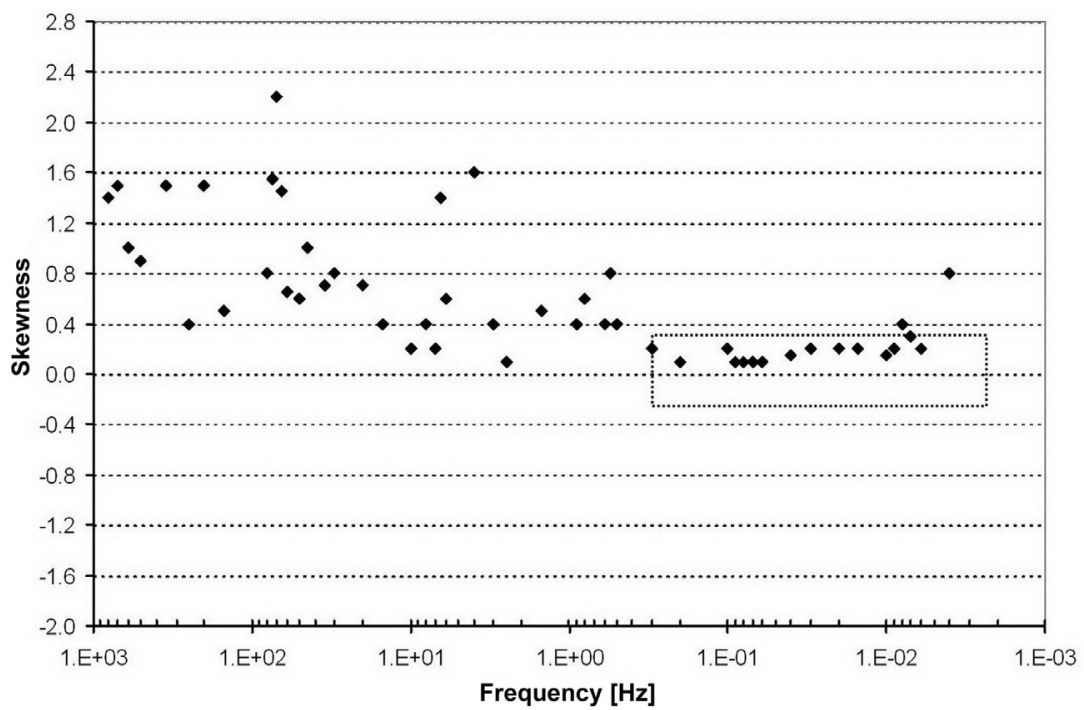

Fig. 3. Distribution of the skewness coefficients versus frequency; the rectangle delimitates the frequency range where skewness coefficients are less than 0.3 and means that the geological structure is of $2 \mathrm{D}$ type.

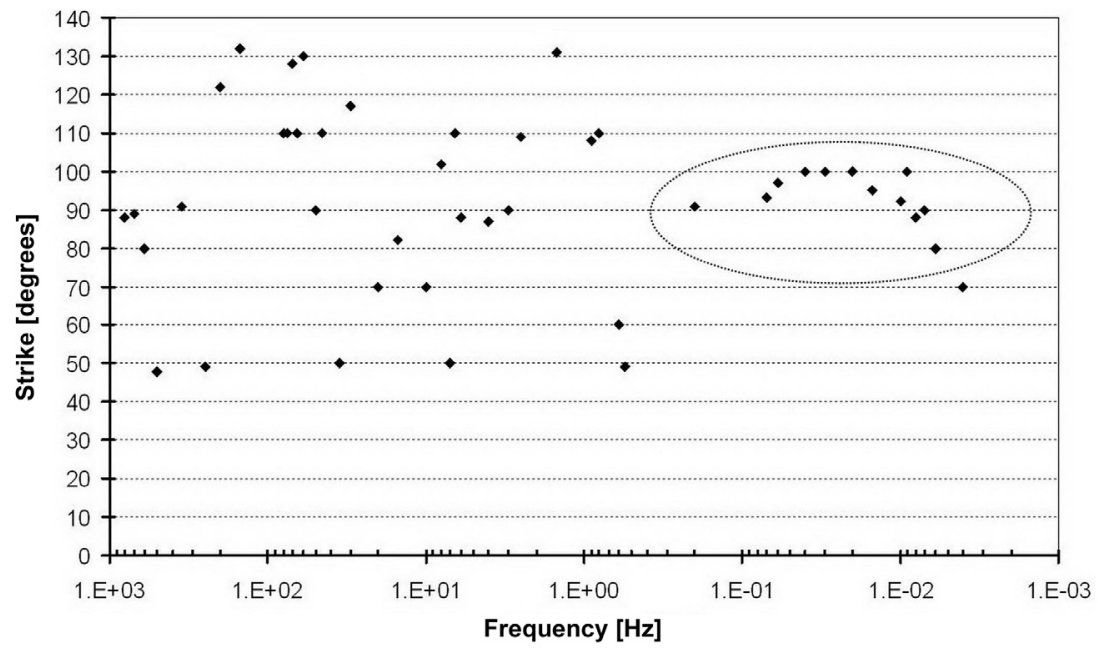

Fig. 4. Distribution of the strike orientation versus frequency; the ellipse delimitates the frequency range where the strike orientation is about east-west.

where: Zxy, Zyx are principal impedances and Zxx, Zyy are additional impedances. The skewness should be $<0.3$ to interpret the structure as 2D (Bahr 1988).

The GOPS is placed, to south-west, at about $100 \mathrm{~km}$ from the Vrancea zone, and to North, $80 \mathrm{~km}$ from the city of Bucharest. The criteria for selection of this observatory are presented above and the following aspects must be included, too:

- It is far enough from the seismogenic zone (about $100 \mathrm{~km}$ ), so that the Bzn is not affected by the earthquakes of magnitude less than 3.0 (a working hypothesis chosen in an initial research stage, in order to determine the suitable distance);

- The existence of a logistics base (a former school) able to supply an optimal monitoring of geomagnetic data and wireless connection for data transfer to Bucharest.

\subsection{Installation of the Measuring System for Continu- ous Monitoring of the Geomagnetic Field}

The continuous monitoring of the geomagnetic components Bz, Bperp and Bpar at the GOPS was accomplished by using the recording system MAG03 DAM (Bartington England), with 6 channel, 24 bit resolution for the collection of data from three axis magnetic field sensor MAG03 MSL, data transmitted to the computer via an optically isolated RS232 serial link. In order to carry out the Bperp, one of the horizontal components of the three axis magnetic sensor has always been orientated perpendicular to the strike. 
The parameters of the data acquisition card are under software control and additional program collects data at each one-minute and stores them on the laptop disk (Table 1).

An example of the geomagnetic time series recorded at the GOPS is presented in Fig. 5.

\subsection{Results}

Some examples are shown to assess the robustness of the presented methodology. It means that the selected normalized Bzn function has been analysed, complying with temporal invariability criterion for a $2 \mathrm{D}$ geoelectric structure in non-seismic condition, taking into consideration just its daily mean distribution versus seismic events acquired in a span of several years.

Three particular cases of the Bzn's distribution obtained for the frequency range less than $1.666 \times 10^{-2} \mathrm{~Hz}$ and correlated with intermediate depth seismic activity are shown in the next examples.

Figure 6 shows time series obtained within a 30 day interval (November 2002), characterized by two domains of maximum, with increased values of 1.874 (Domain 1)

Table1. Geomagnetic time series Bperp, Bpar and Bz recorded on 20 August 2008 (30 minutes record).

\begin{tabular}{|c|c|c|c|c|}
\hline $\begin{array}{c}\text { Date } \\
\text { (month-day-year) }\end{array}$ & $\begin{array}{c}\text { Time } \\
\text { (hour:minute:second) }\end{array}$ & $\begin{array}{c}\text { Bperp } \\
(\text { nT) }\end{array}$ & $\begin{array}{c}\text { Bpar } \\
(\text { nT) }\end{array}$ & $\begin{array}{c}\mathrm{Bz} \\
(\mathrm{nT})\end{array}$ \\
\hline 08-20-2008 & 0:00:29 & 22954 & 262 & 42265 \\
\hline 08-20-2008 & 0:01:28 & 22954 & 262 & 42265 \\
\hline 08-20-2008 & 0:02:28 & 22953 & 262 & 42265 \\
\hline 08-20-2008 & 0:03:28 & 22953 & 262 & 42265 \\
\hline 08-20-2008 & 0:04:28 & 22952 & 262 & 42265 \\
\hline 08-20-2008 & 0:05:28 & 22952 & 262 & 42265 \\
\hline $08-20-2008$ & $0: 06: 28$ & 22952 & 263 & 42265 \\
\hline 08-20-2008 & 0:07:28 & 22952 & 263 & 42264 \\
\hline 08-20-2008 & 0:08:30 & 22951 & 263 & 42264 \\
\hline 08-20-2008 & 0:09:30 & 22951 & 263 & 42264 \\
\hline 08-20-2008 & $0: 10: 28$ & 22951 & 263 & 42264 \\
\hline 08-20-2008 & $0: 11: 28$ & 22952 & 262 & 42265 \\
\hline 08-20-2008 & $0: 12: 28$ & 22952 & 262 & 42264 \\
\hline 08-20-2008 & $0: 13: 28$ & 22952 & 262 & 42264 \\
\hline 08-20-2008 & $0: 14: 28$ & 22952 & 262 & 42264 \\
\hline 08-20-2008 & $0: 15: 28$ & 22952 & 261 & 42265 \\
\hline 08-20-2008 & $0: 16: 28$ & 22952 & 261 & 42264 \\
\hline 08-20-2008 & $0: 17: 28$ & 22952 & 261 & 42264 \\
\hline 08-20-2008 & $0: 18: 28$ & 22952 & 261 & 42264 \\
\hline 08-20-2008 & $0: 19: 28$ & 22951 & 261 & 42264 \\
\hline 08-20-2008 & $0: 20: 28$ & 22951 & 261 & 42264 \\
\hline 08-20-2008 & $0: 21: 28$ & 22951 & 261 & 42264 \\
\hline 08-20-2008 & $0: 22: 28$ & 22951 & 261 & 42264 \\
\hline 08-20-2008 & $0: 23: 28$ & 22951 & 261 & 42264 \\
\hline 08-20-2008 & $0: 24: 28$ & 22951 & 261 & 42264 \\
\hline 08-20-2008 & $0: 25: 28$ & 22951 & 261 & 42264 \\
\hline 08-20-2008 & $0: 26: 28$ & 22952 & 261 & 42264 \\
\hline $08-20-2008$ & $0: 27: 28$ & 22951 & 262 & 42264 \\
\hline 08-20-2008 & $0: 28: 28$ & 22951 & 262 & 42264 \\
\hline 08-20-2008 & $0: 29: 28$ & 22950 & 262 & 42264 \\
\hline 08-20-2008 & $0: 30: 28$ & 22950 & 262 & 42264 \\
\hline
\end{tabular}




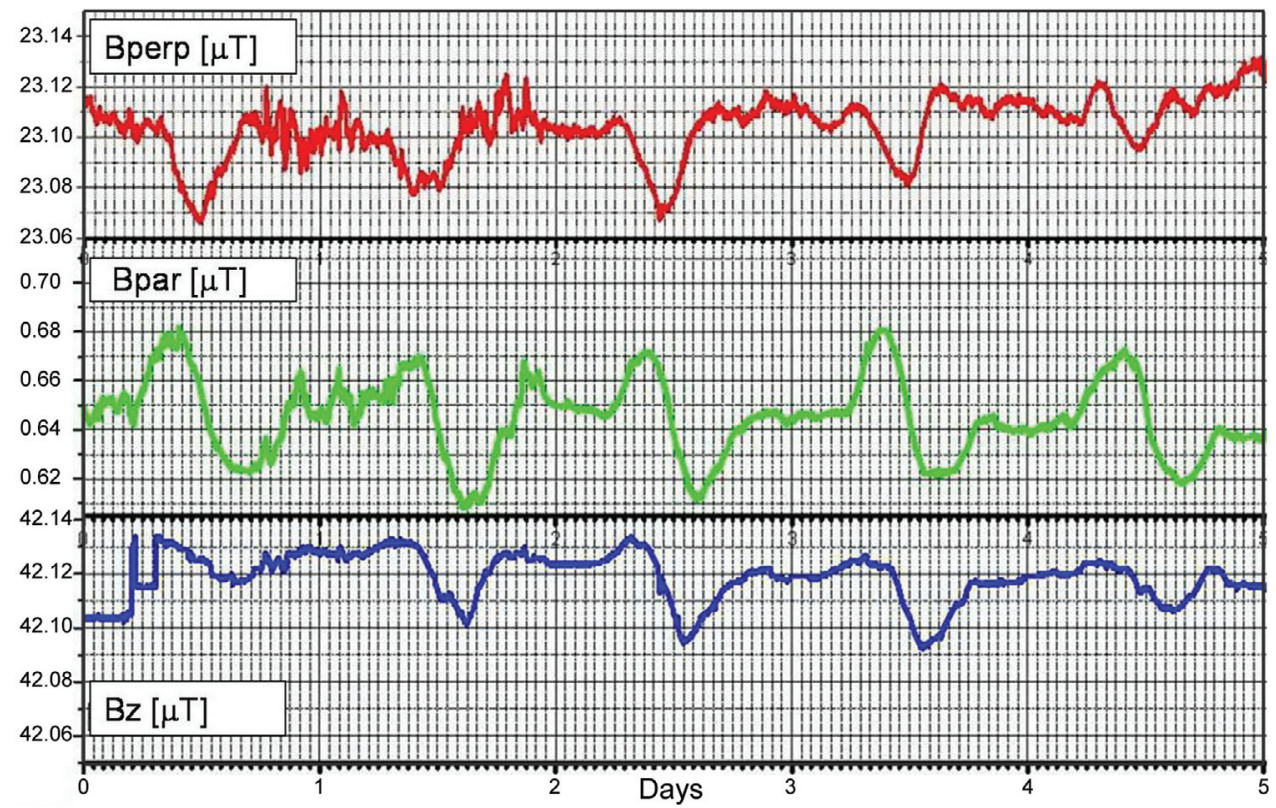

Fig. 5. Geomagnetic time series (Bperp, Bpar and Bz) recorded at the GOPS.

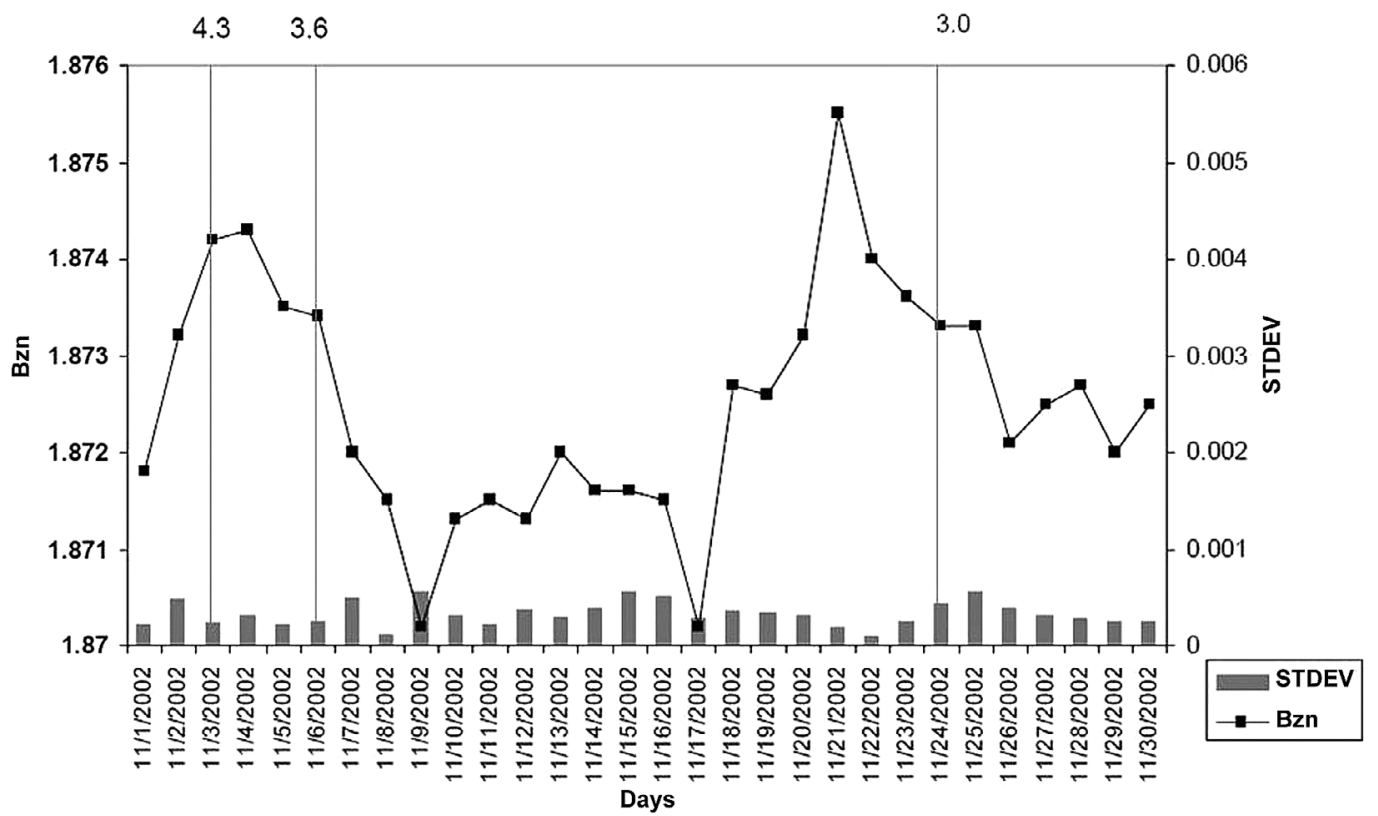

Fig. 6. Daily mean distribution of the normalized function Bzn (November 2002) correlated with intermediate depth seismic events (vertical lines) having marked their magnitude; the line of $1.870( \pm 0.0005)$ is normal distribution in a non seismic condition.

and 1.875 (Domain 2), separated by a non seismic interval extended on 8 days ( 9 - 17 November), where the normal values of Bzn are about $1.870( \pm 0.0005)$. The both domains are correlated with three seismic events having $4.3,3.6$, and 3.0 respectively, in magnitude.

Figure 7 refers to a span of two months (September - October 2004) and emphasizes four instability domains, with increased values of about 1.878 (Domains 1, 2, and 3) and 1.879 (Domain 4). Unlike the case presented in
Figure 6, here, both the instability and stability intervals are very close and, therefore, the corresponding domains are superimposed owing to the multitude of produced seismic events. The earthquakes occurred in this interval are marked by vertical lines, having values of magnitude oscillating between 3.0 and 6.0. All of them are in good correlation with the instability domains of the Bzn associated to the major changes of electrical conductivity along the submerged high sensitive path developed at lithospheric level. 


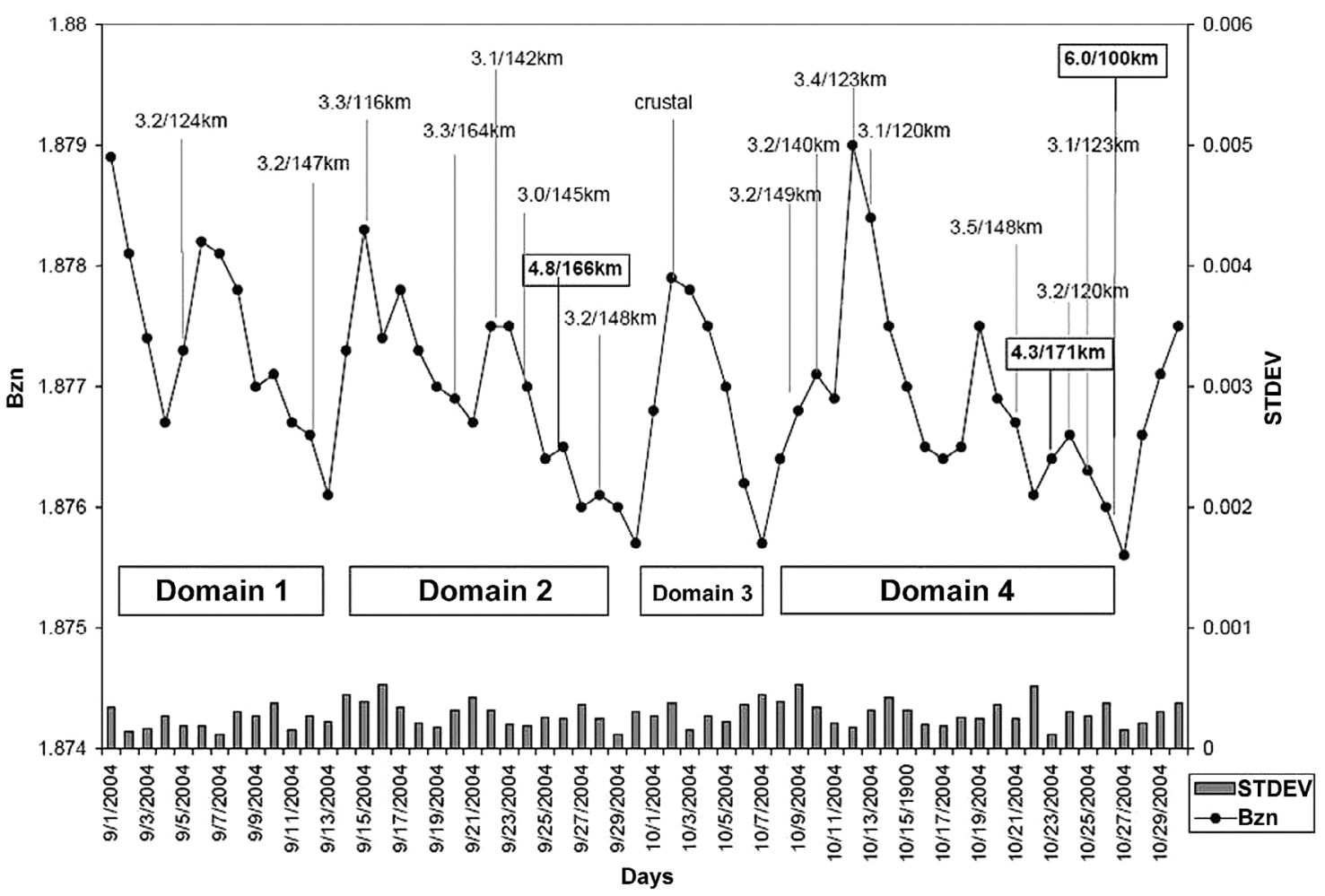

Fig. 7. Daily mean distribution of the normalized function Bzn (September - November 2004) correlated with intermediate depth seismic events (vertical lines) having marked their magnitude and hypocenter depth in $\mathrm{km}$; the line of $1.875( \pm 0.0005)$ is normal distribution in a non seismic condition.

Both Bzn distribution and its standard deviation (Fig. 8), correlated with seismic events occurred during about a month (August 2008), are also represented in order to emphasize a high level of accuracy related to information carried out. In this particular case, the Bzn shows continuous increasing values from 1.832 to 1.843 related to the 9 seismic events occurred at the depth interval of $80-159 \mathrm{~km}$. Standard deviation is less than \pm 0.0005 , except the days 9 , 10 and 19 , where it is about \pm 0.001 .

The normal distribution of the Bzn, obtained in nonseismic conditions prior to EQ, corresponds to the so-called "stable in time" interval. Therefore, taking into account the succession of seismic events occurred in the Vrancea zone, in order to find out the reference value for the anomalous behaviour of Bzn parameter, in a precursory condition, the normal distribution was selected for an interval of some consecutive days without seismic activity. After each seismic event, the reference level (normal distribution) is changed as a sequence of the new physical conditions (maybe due to electrical charge overlap) that could modify the resistivity values along the conductive path into lithosphere.

\section{CONCLUSIONS}

The correlation between the ENF and seismic events occurred in Vrancea zone has pointed out that the interme- diate depth earthquakes are triggered in the ENF instability period, due to the electrical properties variation along the submerged conductive paths (fault systems) through the Earth's lithosphere. These changes of electrical conductivity occurred some days before earthquakes, as consequences of the dehydration and rupturing processes, associated with fluid migration through faulting system inside the Vrancea seismogenic volume and its surrounding areas, are reflected by the anomalous behaviour of the Bzn values.

When the instability (anomalous) and stability domains are very close due to a multitude of seismic events which occurred at short intervals, then correspondent domains are superimposed and maximum amplitude values of the analysed normalized function Bzn may or may not reflect the maximum magnitude of the earthquakes. Therefore, to make an accurate interpretation we have to take into account these constraints regarding the correlation between the function Bzn and seismic events.

Additionally, we have to mention that this kind of research has been conducted in Romania since 2001. According to the above mentioned conclusions, at present, it is not yet possible to make any predictable correlation between the magnitude of seismic event and the amplitude/shape of the Bzn, because of the lack of sufficient data concerning extreme events $(M>6)$, but there is a chance to take a step forward in this direction. 


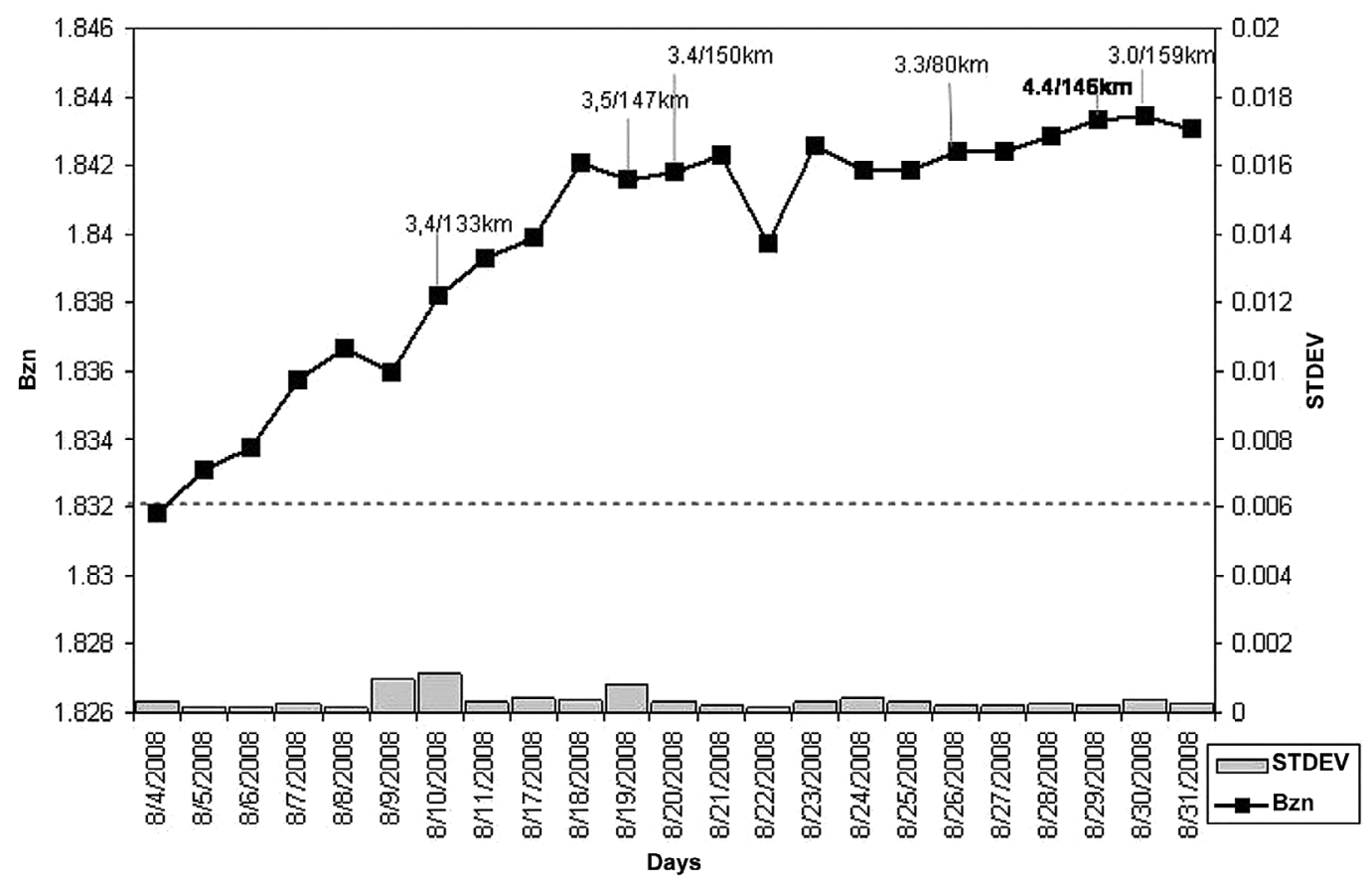

Fig. 8. Daily mean distribution of the normalized function Bzn (August 2008) correlated with intermediate depth seismic events (vertical lines) having marked their magnitude/hypocenter depth in $\mathrm{km}$; the line of $1.832( \pm 0.0005)$ is normal distribution in a non seismic condition; STDEV is standard deviation.

Acknowledgements This study was supported by the Ministry of Education and Research, National Centre of Programs Management, in the frame of the National Programme II - Ideas, Project code 14/2008. The authors are grateful to Alexander Soloviev and the two anonymous reviewers for their comments and useful suggestions.

\section{REFERENCES}

Bahr, K., 1988: Interpretation of the magnetotelluric impedance tensor: Regional induction and local telluric distortion. J. Geophys., 62, 119-127.

Constantinescu, L. and D. Enescu, 1984: A tentative approach to possibly explaining the occurrence of the Vrancea earthquakes. Rev. Roum. Geol. Geophys. Geogr., 28, 19-32.

Fraser-Smith, A. C., A. Bernardi, P. R. McGhill, M. E. Ladd, R. A. Helliwell, and O. G. Villard, Jr., 1990: Low-frequency magnetic field measurements near the epicenter of the Ms 7.1 Loma Prieta earthquake. Geophys. Res. Lett., 17, 1465-1468, doi: 10.1029/GL0 17i009p01465. [Link]

Freund, F., A. Gupta, S. J. Butow, and S. Tenn, 1999: Molecular Hydrogen and dormant charge carriers in minerals and rocks. In: Hayakawa, M. (Ed.), Atmospheric and Ionospheric Electromagnetic Phenomena Associated with Earthquakes. Terra Sci. Publ. Comp., Tokyo, 859-871.
Fujinawa, Y. and K. Takahashi, 1994: Anomalous VLF subsurface electric field changes preceding earthquakes. Technical note of the National Research Institute for Earth Science and Disaster Prevention, 166, 61-75.

Hattori, K., 2004: ULF geomagnetic changes associated with large earthquakes. Terr. Atmos. Ocean. Sci., 15, 329-360.

Hattori, K., H. Ishikawa, M. Harada, I. Takahashi, and C. Yoshino 2008: ULF electromagnetic signature possibly generated under the ground. Abstracts Vol. EMSEVDEMETER Joint Workshop, Sinaia, Romania, 31.

Linzer, H. G., 1996: Kinematics of retreating subduction along the Carpathian arc, Romania. Geology, 24, 167170, doi: 10.1130/0091-7613(1996)024<0167:KORSA T>2.3.CO;2. [Link]

Liu, J. Y., Y. I. Chen, Y. B. Tsai, and Y. J. Chuo, 2000: Seismo-ionospheric signatures prior to $\mathrm{M} \geq 6.0$ Taiwan earthquakes. Geophys. Res. Lett., 27, 3113-3116, doi: 10.1029/2000GL011395. [Link]

Martin, M., J. R. Ritter, and the CALIXTO working group, 2005: High-resolution teleseismic body-wave tomography beneath SE Romania - I. Implication for three-dimensional versus one-dimensional crustal correction strategies with a new crustal velocity model. Geophys. J. Int., 162, 448-460, doi: 10.1111/j.1365246X.2005.02661.x. [Link]

Nagao, T., Y. Orihara, T. Yamaguchi, I. Takahashi, K. 
Hattori, Y. Noda, K. Sayanaghi, and S. Uyeda, 2000: Co-seismic geoelectric potential changes observed in Japan. Geophys. Res. Lett., 27, 1535-1538, doi: 10.1029/1999GL005440. [Link]

Nagao, T., Y. Enomoto, Y. Fujinawa, M. Hata, M. Hayakawa, Q. Huang, J. Izutsu, Y. Kushida, K. Maeda, K. Oike, S. Uyeda, and T. Yoshino, 2002: Electromagnetic anomalies associated with 1995 Kobe earthquake. J. Geodyn., 33, 401-411, doi: 10.1016/S02643707(02)00004-2. [Link]

Oncescu, M. C., V. Burlacu, M. Anghel, and V. Smalbergher, 1984: Three-dimensional P-wave velocity image under Carpathian Arc. Tectonophysics, 106, 305-319, doi: 10.1016/0040-1951(84)90182-3. [Link]

Rikitake, T., 1997: Nature of electromagnetic emission precursory to an earthquake. J. Geomag. Geoelectr., 49, 1153-1163.

Saroso, S., K. Hattori, H. Ishikawa, Y. Ida, R. Shirogane, M. Hayakawa, K., Yumoto, K. Shiokawa, and M. Nishihashi, 2009: ULF geomagnetic anomalous changes possibly associated with 2004-2005 Sumatra earthquakes. Phys. Chem. Earth, 34, 343-349, doi: 10.1016/j.pce.2008.10.065. [Link]

Soloviev, A. A., I. A. Vorobieva, and G. F. Panza, 1999: Modelling of Block-structure dynamics: Parametric study for Vrancea. Pure Appl. Geophys., 156, 395-420, doi: 10.1007/s000240050305. [Link]

Sperner, B., F. Lorenz, K. Bonjer, S. Hettel, B. Muller, and F. Wenzel, 2001: Slab break-off - abrupt cut or gradual detachment? New insights from the Vrancea region (SE Carpathians, Romania). Terr. Nova, 13, 172-179, doi: 10.1046/j.1365-3121.2001.00335.x. [Link]

Stanica, M., D. Stanica, and C. Marin-Furnica, 1999: The placement of the Trans-European Suture Zone on the Romanian territory. Earth Planets Space, 51, 10731078.

Stanica, D., M. Stanica, and D. Zugravescu, 2004a: The electromagnetic precursory phenomena associated with the earthquakes occurred in the Vrancea seismogenic zone. Studi Geologici Camerti, Special Issue: Active Faults: Analysis processes and monitoring, EDIMOND, Italy, 133-136.

Stanica, D., M. Stanica, L. Piccardi, E. Tondi, and G. Cello, 2004b: Evidence of geodynamic torsion in the Vrancea zone (Eastern Carpathians). Rev. Roum. Géophys., 48, 15-19.

Stanica, D., M. Stanica, M. Visan, and M. Popescu, 2006: Anomalous behavior of the electromagnetic parameters associated to intermediate depth earthquakes. Rev. Roum. Géophys., 50, 41- 47.

Stanica, D. and M. Stanica, 2007: Electromagnetic monitoring in geodynamic active areas. Acta Geodynamica et Geomaterialia, 4, 99-107.

Trifu, C. I. and M. Radulian, 1989: Asperity distribution and percolation as fundamentals of earthquakes cycle. Phys. Earth Planet. Inter., 58, 277-288, doi: 10.1016/0031-9201(89)90100-3. [Link]

Uyeda, S., K. S. Al-Damegh, E. Dologlou, and T. Nagao, 1999: Some relationship between VAN seismic electric signals (SES) and earthquake parameters. Tectonophysics, 304, 41-55, doi: 10.1016/S0040-1951 (98)00301-1. [Link]

Uyeda, S., T. Nagao, Y. Orihara., T. Yamaguchi, and I. Takahashi, 2000: Geoelectric potential changes: Possible precursors to earthquakes in Japan. Proc. Natl. Acad. Sci., 97, 4561-4566, doi: 10.1073/pnas.97.9.4561. [Link]

Uyeda, S., T. Nagao, and M. Kamogawa, 2009: Short-term earthquake prediction: Current status of seismo-electromagnetics. Tectonophysics, 470, 205-213. [Link]

Varotsos, P., K. Eftaxias, F. Vallianatos, and M. Lazaridou, 1996: Basic principles for evaluating an earthquake prediction method. Geophys. Res. Lett., 23, 1295-1298, doi: 10.1029/96GL00905. [Link]

Varotsos, P. A., 2005: The physics of seismic electric signals, TERRAPUB, Tokyo, $338 \mathrm{pp}$.

Word, D. R., H. W. Smith, and F. X. Bostick, Jr., 1970: An investigation of the magnetotelluric tensor impedance method, Electronics Research Center, The University of Texas at Austin, Austin, Texas 78712, 242 pp.

Yen, H. Y., C. H. Chen, Y. H. Yeh, J. Y. Liu, C. R. Lin, and Y. B. Tsai, 2004: Geomagnetic fluctuations during the 1999 Chi-Chi earthquake in Taiwan. Earth Planets Space, 56, 39-45.

Zeng, X., Y. Lin, C. Xu, and S. O. Yang, 2001: Turning changes in evolution of geomagnetic field and infrastructural analysis of earthquake prediction. Kybernets- Int. J. Systems \& Cybernetics, 30, 365-377. 